\title{
POST-CURE'S EFFECT ON THE DEPTH OF CURE OF A SHORT FIBER-REINFORCED RESIN COMPOSITE
}

\author{
ELLYZA HERDA*, NADIA SAFIRA NINDA, MIA DAMIYANTI
}

Department of Dental Materials, Faculty of Dentistry, Universitas Indonesia, Jakarta, Indonesia. Email: ellyza_herda@yahoo.com Received: 16 September 2017, Revised and Accepted: 3 October 2017

\begin{abstract}
Objective: This study aimed to identify post-cure's effect on the depth of cure (DOC) of a short fiber-reinforced resin composite (SFRC).

Methods: Six EverX Posterior ${ }^{\mathrm{TM}}$ shade A3 specimens were cured with a light-emitting diode light curing unit with $800 \mathrm{~mW} / \mathrm{cm}^{2}$ of light irradiation for $20 \mathrm{~s}$. The specimens were divided into two groups. The first was measured immediately post-cure and the second was measured 24 -h post-cure. They were measured with a Vickers microhardness profile test. An independent t-test was used to analyze the significance of the differences between
\end{abstract} the DOC value and different variables.

Results: The DOC of the specimens measured immediately post-cure was $3.02 \pm 0.02 \mathrm{~mm}$. The DOC of the specimens measured 24 -h post-cure was $3.93 \pm 0.03 \mathrm{~mm}$.

Conclusion: The DOC of the specimens measured 24-h post-cure was significantly higher than the DOC of the specimens measured immediately postcure. Post-cure polymerization (24-h post-cure) can increase the DOC values of an SFRC.

Keywords: Short fiber-reinforced resin composite, Depth of cure, Post-cure.

(C) 2017 The Authors. Published by Innovare Academic Sciences Pvt Ltd. This is an open access article under the CC BY license (http://creativecommons. org/licenses/by/4. 0/) DOI: http://dx.doi.org/10.22159/ijap.2017.v9s2.43

\section{INTRODUCTION}

Fiber-reinforced resin composites have been used for post crowns, periodontal splints, and reparative materials in removable dentures [1]. Short fiber-reinforced resin composites (SFRCs) have been developed as substructures in posterior restorations. SFRCs have a fracture toughness equal to that of dentin, so they can be used as substructures in posterior restorations [2-4]. Light-polymerized resin composites must undergo polymerization to solidify. During polymerization, monomers are transformed into polymers [5]. Polymerization occurs in light-polymerized resin composites when curing continues after the curing process has begun (post-cure). Post-cure polymerization begins quickly (within $24 \mathrm{~h}$ ) and continues slowly [6]. Polymerization is influenced by three main factors: Lightwave length, light intensity, and curing duration [7]. Post-cure polymerization can increase the hardness and depth of cure (DOC) values of a resin composite, thereby affecting the success of the restoration. Inadequate polymerization will reduce the physical properties of a resin composite restoration because there are many non-reactive monomers [6,8]. Polymerization decreases as restoration depth increases. DOC is influenced by the post-cure period; the irradiation distance; the size and distribution of the filler; and the type, color, and thickness of the resin composite $[9,10]$.

DOC increases as the post-cure polymerization reaction continues [11]. In vitro studies have shown that several methods can be used to measure DOC, including optical microscopy, fourier transform infrared (FTIR) spectroscopy, bottom-to-top surface-hardness ratio, the ISO 4049, and the Vickers microhardness profile test [7]. The bottom-to-top surface-hardness ratio and optical microscopy methods overestimate DOC; the FTIR method is less sensitive when measuring slight changes in the degree of conversion [12]. DOC is also overestimated by the ISO 4049 method, unlike the Vickers microhardness profile test [13]. For example, a previous study investigated DOC using four bulk-fill materials. It measured the DOC using the ISO 4049 method and the Vickers microhardness profile test. The study showed that the ISO 4049 method overestimated the materials' DOCs, unlike the
Vickers microhardness profile test [13]. Consequently, the Vickers microhardness profile test is more accurate when measuring DOC than other methods $[12,13]$.

A previous study investigated the post-cure polymerization of a microfill resin composite stored at $37 \pm 2{ }^{\circ} \mathrm{C}$. The bottom-to-top surfacehardness ratio showed that the hardness value increased as the postcure duration increased. In addition, there was a higher degree of conversion, which increased as the post-cure duration increased. The conversion was slow for $20 \mathrm{~min}$ after irradiation. It gradually increased 60 min after irradiation and continued to increase 1-7 days after irradiation [11].

A study of the exposure time and post-cure of a microhybrid resin composite was conducted. The composite's nanohardness, Young's modulus, and degree of conversion were measured immediately after irradiating the composite and storing it at $37^{\circ} \mathrm{C}$ for 7 days post-cure. The study found that the composite's nanohardness, Young's modulus, and degree of conversion increased when the composite was stored under those conditions [14].

A study investigated the DOCs of five types of bulk-fill resin composites. The composites were stored at $37^{\circ} \mathrm{C}$ for 24 -h post-cure and were measured using a Vickers hardness profile test. The DOC was determined to be at least $80 \%$ of the maximum value of the Vickers hardness number (VHN). The study reported that the five types of bulkfill resin composites could reach a DOC that matched the manufacturer's declaration after being stored at $37^{\circ} \mathrm{C}$ for 24 -h post-cure [7].

Another study investigated 24-h post-cure polymerization and the effect temperature has on particulate and bulk-fill resin composites. The composites were stored at $20^{\circ} \mathrm{C}$ and $37^{\circ} \mathrm{C}$. A spectrometer reported a significant increase in the degree of conversion 24-h post-cure [15]. While such research has been conducted, no studies have examined post-cure's effect on the DOC of SFRCs. Thus, this study investigated the topic. 


\section{METHODS}

Six specimens were prepared in a stainless steel mold that contained a bottom plate, a top plate, and a $10 \mathrm{~mm} \times 4 \mathrm{~mm} \times 2 \mathrm{~mm}$ slot (Fig. 1). The specimens consisted of a random SFRC, which was EverX Posterior ${ }^{\mathrm{TM}}$ (GC Corp, Tokyo, Japan). It was shade A3 cured with a light-emitting diode (LED) light curing unit (LCU) (Litex 695, USA) with light irradiation of $800 \mathrm{~mW} / \mathrm{cm}^{2}$ for $20 \mathrm{~s}$. The specimens were divided into two groups: Group 1 was specimens at room temperature $\left(23 \pm 1^{\circ} \mathrm{C}\right)$, which were measured immediately post-cure using the surface microhardness profile method and Group 2 was specimens stored dry at $37^{\circ} \mathrm{C}$, which were measured 24 -h post-cure using the surface microhardness profile method. The results of Group 1 were compared to the results of Group 2 to determine differences in the DOC values for the SFRCs, depending on the curing method used.

All specimens were examined with a microhardness instrument (a Zwick/RoellZH $\mu$ microhardness tester, Germany). A fixed load of $200 \mathrm{~g}$ was applied for $15 \mathrm{~s}$. The VHN was measured at $0.3 \mathrm{~mm}$ intervals from the surface that was close to the LCU. The VHN was measured until the indentation on the specimen's surface was not clear enough to be measured. The data were calculated as hardness numbers, and the VHN was plotted against the DOC (in mm) [7].An independent t-test was used to analyze the significance of the differences between the DOC

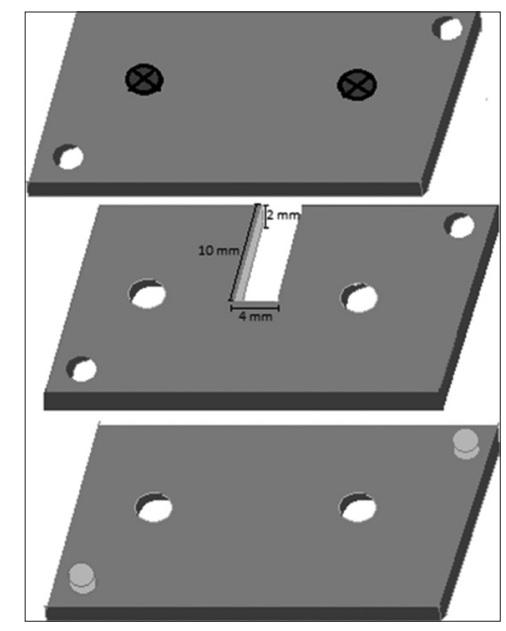

Fig. 1: The stainless steel mold, which contained a bottom plate, a top plate, and a slot measuring $10 \mathrm{~mm} \times 4 \mathrm{~mm} \times 2 \mathrm{~mm}$ value and different variables. All data were subjected to a normality test and Levene's test of homogeneity of variance $(\alpha=0.05)$ following the assumption there were equal variances.

\section{RESULTS}

The maximum VHNs, $80 \%$ of the maximum VHNs, and the DOCs of the SFRCs are presented in Table 1 and shown in Fig. 2. The maximum VHNs were acquired by measuring at $0.3 \mathrm{~mm}$ intervals. The VHNs were $57.4 \pm 0.38$ for Group 1 and $61.4 \pm 0.87$ for Group 2 . The $80 \%$ of maximum VHN measurements were $45.9 \pm 0.3$ for Group 1 and $49.1 \pm 0.7$ for Group 2. The depths corresponding to $80 \%$ of the maximum VHN were $3.02 \pm 0.02$ for Group 1 and $3.93 \pm 0.03$ for Group 2. The depths were taken as the DOCs.

\section{DISCUSSION}

In this study, the DOC of each specimen was measured by determining its VHN profile. There were significant differences between the groups' DOCs. The DOCs of Group 2's specimens were higher. This is due to the post-cure polymerization reaction, which limited monomer movement and trapped free radicals in the unpolymerized resin composite matrix [14].

The manufacturer of the SFRC claimed that the composite's DOC was $4 \mathrm{~mm}$ [8]. The results showed the DOC was $3.02 \pm 0.02 \mathrm{~mm}$ when measured immediately post-cure and $3.93 \pm 0.03 \mathrm{~mm}$ when measured 24-h post-cure. The difference between the study's result and the manufacturer's claim may have been caused by measuring method differences or inadequate polymerization. The manufacturer used the ISO 4049 method to measure the DOC. According to a previous study, the ISO 4049 method overestimates DOC; the Vickers microhardness profile test is more accurate $[12,13]$.

As aforementioned, polymerization is affected by light wavelength, light intensity, and curing duration [7]. This study used an LED-LCU with an irradiation of $800 \mathrm{~mW} / \mathrm{cm}^{2}$. The SFRCs manufacturer recommended $20 \mathrm{~s}$ of exposure time with an irradiation $800 \mathrm{~mW} / \mathrm{cm}^{2} \mathrm{LCU}$ to achieve a $4 \mathrm{~mm}$ DOC $[8,9]$. The results of this study indicate that such an irradiation and exposure time cannot produce a $4 \mathrm{~mm}$ DOC.

An increase in light exposure duration would not improve the physical properties of the resin composite because the total time required for the resin composite to achieve its maximum hardness is 24 -h post-cure [11]. The wavelength of an LCU can generate an optimal polymerization when it's similar to resin composite's photoinitiator. LED-LCU has a

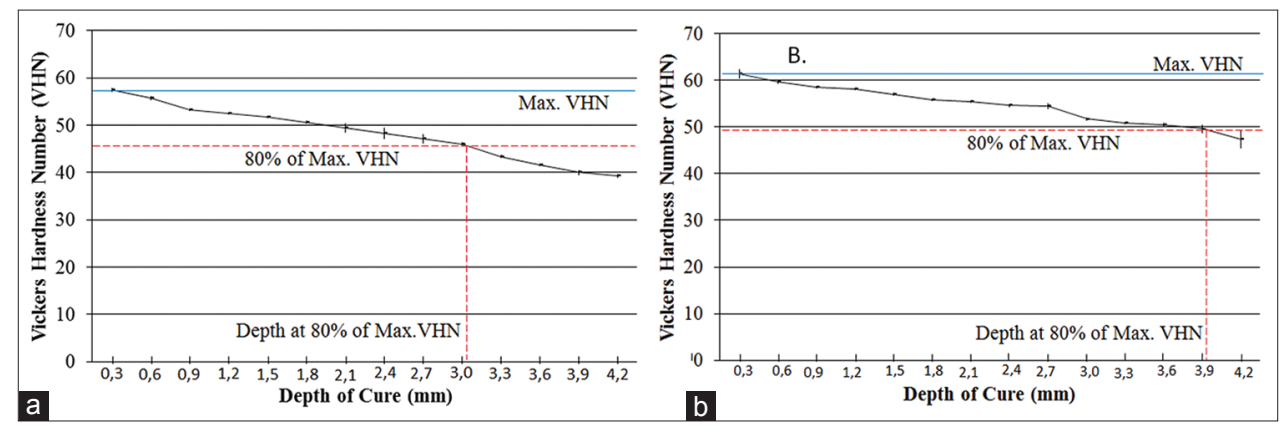

Fig. 2: (a,b) Vickers hardness numbers and depth of cures. A shows Group 1's and B shows Group 2's

Table 1: The SFRCs' mean VHNs and DOCs

\begin{tabular}{llllll}
\hline Groups & Maximum & $\mathbf{8 0 \%}$ of maximum VHN & DOC (mm) & Minimum DOC (mm) & Maximum DOC (mm) \\
& VHN & & & & \\
\hline Group 1 (immediately post-cure) & $57.4 \pm 0.38$ & $45.9 \pm 0.3$ & $3.02 \pm 0.02^{*}$ & 3.00 & 3.04 \\
Group 2 (24-h post-cure) & $61.4 \pm 0.87$ & $49.1 \pm 0.7$ & $3.93 \pm 0.03^{*}$ & 3.90 & 3.96 \\
\hline
\end{tabular}

${ }^{*}$ Significant $(\mathrm{p}<0.05)$. VHN: Vickers hardness number, DOC: Depth of cure, SFRCs: Short fiber-reinforced resin composites 
similar wavelength with the resin composite's photoinitiator which is camphorquinone [16]. This study used an LED-LCU to activate the SFRC which contain camphoroquinone as the photoinitiator.

Polymerization can influence the degree of conversion that affects DOC. DOC is influenced by color, the post-cure period, the resin composite type, the distance of the irradiation, the thickness of resin composite, and the sizes and distributions of the filler particles $[9,10]$.

The results of this study showed that there was a significant increase in the hardness and DOC of SFRC stored at $37 \pm 1^{\circ} \mathrm{C}$ for $24 \mathrm{~h}$. The results are in accordance with Mohamad et al.'s study. Their study showed an increase in the hardness of a particulate resin composite stored at $37^{\circ} \mathrm{C}$ for 7 days. During polymerization, free radical molecules that had not reacted were trapped within the polymer network due to a rapid increase in viscosity. During the post-cure period, the free radicals could move and touch species that reacted in the polymer network [14].

This study used the Vickers hardness profile method to measure DOC. The hardness was measured at $0.3 \mathrm{~mm}$ intervals at $10 \pm 1 \mathrm{~min}$ postcure. It was also measured at $4.2 \mathrm{~mm}$ intervals at $120 \pm 20 \mathrm{~min}$ postcure for Group 1 and 24-h post-cure for Group 2. Group 1 and Group 2 had irregular indentations after $4.2 \mathrm{~mm}$ intervals, so the last hardness entered into the study's data was at $4.2 \mathrm{~mm}$. The study showed SFRC could produce a high DOC of $3.93 \pm 0.03 \mathrm{~mm} 24$-h post-cure. Therefore, the maximum recommended SFRC thickness is $3.5-4 \mathrm{~mm}$.

\section{CONCLUSION}

Post-cure polymerization (24-h post-cure) can increase the DOC of an SFRC. The DOC increases significantly to $3.93 \pm 0.03 \mathrm{~mm}$.

\section{ACKNOWLEDGMENTS}

This work's materials were partly provided by GC Indonesia. The publication of this manuscript is supported by Universitas Indonesia.

\section{REFERENCES}

1. Garoushi S, Lassila LV, Vallittu PK. Fibre-reinforced composite in clinical dentistry. Chin J Dent Res 2009;12:7-14
2. Garoushi S, Vallittu PK, Lassila LV. Use of short fiber-reinforced composite with semi-interpenetrating polymer network matrix in fixed partial dentures. J Dent 2007;35:403-8.

3. Garoushi S, Tanner J, Vallittu P, Lassila L. Preliminary clinical evaluation of short fiber-reinforced composite resin in posterior teeth: 12-months report. Open Dent J 2012;6:41-5.

4. Garoushi S, Säilynoja E, Vallittu PK, Lassila L. Physical properties and depth of cure of a new short fiber reinforced composite. Dent Mater 2013;29:835-41.

5. Albers HF. Tooth-colored Restoratives: Principles and Techniques. $9^{\text {th }}$ ed. British Columbia: Decker Inc.; 2002.

6. Leprince J, Lamblin G, Truffier-Boutry D, Demoustier-Champagne S, Devaux J, Mestdagh M, et al. Kinetic study of free radicals trapped in dental resins stored in different environments. Acta Biomater 2009;5:2518-24

7. Alrahlah A, Silikas N, Watts DC. Post-cure depth of cure of bulk fill dental resin-composites. Dent Mater 2014;30:149-54.

8. GC Europe. Ever X Posterior FAQ. Belgium: GC Europe; 2013. Available from: http://www.dibateb.com/wp-content/uploads/2016/01/ FAQ-everx-posterior.pdf 16. [Last accessed on 2016 May 30]

9. Moore BK, Platt JA, Borges G, Chu TM, Katsilieri I. Depth of cure of dental resin composites: ISO 4049 depth and microhardness of types of materials and shades. Oper Dent 2008;33:408-12.

10. Krämer N, Lohbauer U, García-Godoy F, Frankenberger R. Light curing of resin-based composites in the LED era. Am J Dent 2008;21:135-42.

11. Leung RL, Fan PL, Johnston WM. Post-irradiation polymerization of visible light-activated composite resin. J Dent Res 1983;62:363-5.

12. DeWald JP, Ferracane JL. A comparison of four modes of evaluating depth of cure of light-activated composites. J Dent Res 1987;66:727-30

13. Flury S, Hayoz S, Peutzfeldt A, Hüsler J, Lussi A. Depth of cure of resin composites: Is the ISO 4049 method suitable for bulk fill materials? Dent Mater 2012;28:521-8.

14. Mohammad D, Young RJ, Mann AB, Watts DC. Post-polymerization of dental resin composite evaluated with nanoindentation and microraman spectroscopy. Arch Orofac Sci 2007;2:26-31

15. Par M, Gamulin O, Marovic D, Klaric E, Tarle Z. Effect of temperature on post-cure polymerization of bulk-fill composites. J Dent 2014;42:1255-60.

16. Cunha LG, Alonso RC, Pfeifer CS, de Góes MF, Ferracane JL, Sinhoreti MA, et al. Effect of irradiance and light source on contraction stress, degree of conversion and push-out bond strength of composite restoratives. Am J Dent 2009;22:165-70. 